\title{
Issues on water, manufacturing, and energy sustainability
}

\author{
Heriberto Cabezas $^{1} \cdot$ Yinlun Huang ${ }^{2}$
}

Published online: 9 September 2015

(c) Springer-Verlag Berlin Heidelberg 2015

A special section of this issue of the journal has a selection of papers addressing the themes of Water Sustainability and Innovative Technology, Sustainable Manufacturing, and Sustainable Energy. The papers are filled with closely knitted and mutually interacting research of significant work. They should add great value to readers in the domain of sustainability science and engineering. Researchers in both academic and industrial organizations will benefit from this collection of papers, which is aimed at advancing the current research into a next level for greater economic, environmental, and social benefits.

The Water Sustainability and Innovative Technology theme focused on ensuring a sustainable supply of safe and useful water, which is one of the most critical resource management issues facing the United States and the world. Multidisciplinary, big-picture thinking at the regional and corporate level, combined with macro- and microscale strategies, and plans and actions at the local and plant level, are needed to meet this challenge. The papers highlight public and private sector research, advances, and technology improvements that can help meet these needs, and the role of regional public-private partnerships in the proliferation and implementation of sustainable water practices.

The Sustainable Manufacturing theme focused on the increasing need of companies to look for new ways of making more efficient use of resources, ensuring compliance with domestic and international regulations related to

Heriberto Cabezas

hcabezas@fuse.net

1 Department of Computer Science and Systems Technology, University of Pannonia, Veszprem, Hungary

2 Department of Chemical Engineering and Materials Science, Wayne State University, Detroit, MI, USA environment, safety and health, and enhancing the marketability of their products, processes, and services. While the trend on implementing sustainable manufacturing practices continues to grow, so do the implications for global competitiveness and leadership in manufacturing. The papers highlight cutting edge research, technology development, federal and private sector advances in sustainable manufacturing.

The Sustainable Energy theme focused on integration of sustainable energy and energy efficiency in water technologies and sustainable manufacturing. Energy efficiency and renewable energy are usually considered the twin pillars of sustainable energy. The papers highlight the continued quest for sustained supplies of energy and the roles of technologies for energy use efficiency improvement and GHG emission reduction.

The pursuance of sustainability is about the creation and maintenance of the necessary conditions to support present and future generations. While there are a variety of definitions of sustainability, a key concept and core principle of sustainability is the triple-bottom-line-based balanced development. Therefore, sustainability problems are always very complex. In the perspective on pursuit on sustainability, Diwekar's paper discussed the systems boundaries, and provided a comprehensive review on the systems analysis approaches in various disciplines.

System analysis is essential when investigating water resources management problems. In the paper on urban water resources management, Shuster and Garmestani offer a definition of sustainability based on the ease, with which capital (e.g., natural resource, social, cultural, financial, etc.) can be exchanged or substituted. They then discuss how to examine barriers to the free exchange of capitals that can hinder the realization of sustainable water resources management and how these barriers may be 
recognized and reduced. The paper further explores a possibility of internalizing costs previously externalized to the environment through the cultivation of green infrastructure as a generator of ecosystem services, and its pertinence to sustaining the contemporary urban water cycle.

In the sustainable manufacturing area, there are a number of excellent contributions. Helling indicates the importance of life cycle thinking in industrial innovations. $\mathrm{He}$ explains that the ability to articulate aspirational goals for some areas and quantitative measurements for others is critical. Dow Chemical's experience shows that individual awareness of the themes of sustainable chemistry and engineering is a firm foundation for sustainable innovation.

Industrial experience in sustainability enhancement has shown that solution identification is mostly scenario based, where data and information uncertainty issues are usually not addressed holistically due to inherent problem complexity. In Liu and Huang's paper, a Monte Carlo-based simulation and system optimization method is introduced for deriving sustainability enhancement strategies where uncertainties are systematically taken into account. The methodological efficacy is illustrated through a study on an industrial network involving a number of manufacturing sectors.

While industrial network sustainability is a large-scale problem, sustainability issues should be fully addressed at the process level as well. The paper by Slater et al. is about shear-enhanced microfiltration of microalgae in a vibrating membrane module. The process provides a greener alternative to conventional mechanical and thermal separation systems. Sunol and his industrial collaborators introduce the use of a fluid fluidized bed for nano-layer encapsulation. The process uses circulating supercritical carbon dioxide doped with encapsulating material. It is a novel green process that allows sequential nano-layer deposition.
Energy sustainability can be achieved through promoting sustainable energy including renewable energy sources and also improving energy efficiency. In their paper, Vance et al. present a simple yet rigorous procedure for assessing and counterbalancing the relationship between energy demand, environmental impact, population, GDP, and energy efficiency. Their work emphasizes the challenge in reaching energy sustainability and helps to frame possible solutions to sustainable energy strategies.

The energy-water nexus is the relationship between how much energy it takes to collect, clean, move, store, and dispose of water, and how much water is evaporated to generate and transmit energy. This is a very complex sustainability problem. The paper by Emec et al. introduces an approach for identifying solutions including hybrid energy and water generation to process agricultural products. The production system achieves nearly zero emission, zero water foot-print, and increases the local added value by product-service systems. To support decision making, various technological options are considered, evaluated, and recommendations are made for implementation. Sukumara et al. described a techno-economic analysis tool to validate long-term viability of emerging biofuel manufacturing processes. Application of the tool shows that integration of process simulation and supply chain optimization can be effective in validating the long-term economic viability of a renewable energy process system.

These three sustainability issues were explored at the 2013 International Congress on Sustainability Science and Engineering (ICOSSE'13) held in Cincinnati, Ohio in August 2013. ICOSSE'13 was sponsored by the U.S. National Science Foundation through a grant (Award No. 1322172). 